\title{
Study on the Application of Expressway Construction Based on Sponge City Concept
}

\author{
Yuanzhi Chen \\ Shuxing Construction Technology Co., Ltd. E-mail: shuxing@163.com
}

\begin{abstract}
Currently, in the active trial stage, sponge city concept has been applied in many low-impact development facilities on expressways in China, but many applications are not widely used. From four angles of pavement, slope, interchange and service area of expressway, this paper explains the adverse effects brought by rainwater, and then gives, and it carries out scene analysis combined with actual engineering projects with some feasible application schemes. Finally, the concept of sponge city at present is summarized, and it is considered that the optimal planning and design can be made only after establishing a reliable mathematical model and carrying out quantitative analysis.
\end{abstract}

Keywords: Sponge City; Expressway; Highway Construction

\section{Introduction}

The concept of sponge city was put forward by Chinese scholars for the first time. It is a combination of rainwater management concepts at home and abroad, which is used to promote the utilization of rainwater resources and ecological environment protection. As its name implies, sponge city assumes that the city is like a sponge, which can absorb water, store water and release water through certain transformation. It concentrate rainwater by absorbing water and storing water to reduce the impact of rainfall on cities; By releasing the stored and treated rainwater, it can also be used to conserve groundwater, green plant and irrigate farmland. To sum up, putting sponge city concept into practice can promote the utilization efficiency of rainwater resources, reduction of floods and certain social benefits.

\section{The impact of rain on the expressway}

At present, the rainwater management and control form of expressways in China mainly relies on setting road arches, side ditches, drainage ditches, blind ditches, central drainage pipes, horizontal drainage pipes, rapids and others to discharge rainwater, which makes insufficient use of rainwater and protects the surrounding ecosystem. Rainwater is easy to have a great influence on the roadbed and pavement, slope, interchange and service area of expressway, which will be discussed in detail below. Highway water damage is a major hidden danger that affects the safety and durability of pavement structure. Several common pavement diseases include rutting, network cracking, pits and grooves, instant mortar, subgrade subsidence and so on. The main causes are weak waterproof and drainage capacity of pavement, high porosity of pavement surface layer, untreated foundation in place, etc. The erosion of rainwater will directly discharge pollutants on the pavement surface to both sides of the highway, such as heavy metals, SS, BOD , COD, TN, TP, etc., which should be paid more

\footnotetext{
Copyright (C) 2020 Yuanzhi Chen

doi: $10.18686 /$ utc.v6i1.84

This is an open-access article distributed under the terms of the Creative Commons Attribution Non-Commercial License

(http://creativecommons.org/licenses/by-nc/4.0/), which permits unrestricted non-commercial use, distribution, and reproduction in any medium, provided the original work is properly cited.
} 
attention when the expressway passes through the water source protection area. Grass-planting protection on expressway slope is very common, but its adsorption capacity to rainwater is limited. After heavy rain, slope erosion is often serious. Masonry protection can enhance the stability of the slope, but it only prevents the slope from collapsing. When rainfall is heavy, it is still impossible to keep and store rainwater for utilization, so that it will not flow into the farmland and villages outside the highway.

At present, the design of most expressway interchanges focuses on drainage through pipe networks and culverts. When rainwater comes, there is the risk of soil erosion scouring farmland and polluting fish ponds; At the same time, excessive pursuit of formalism can not be combined with the unique terrain of the interchange for concrete and innovative design, and the variety of green vegetation is relatively single; In addition, large quantities of earth and stone works also increase the risk of disturbance or even destruction of surrounding ecosystems. The traditional concept of "discharge" in expressway service areas in China leads to extremely low utilization rate of rainwater. Because it is far away from cities and towns, the drainage system can only rely on the pipe network prepared during the construction period for drainage. The phenomenon of unsmooth drainage and accumulated water in the service areas often occurs during heavy rain, and rainwater runoff will wash and pollute surrounding agricultural and forestry crops and water bodies. At the same time, because the roof of the service area is hardened and the pavement is mostly cement concrete pavement, the rainwater cannot seep into the soil layer and the peak value of rainwater cannot be reduced. In the non-rainy season, due to less precipitation, the green plants in the service area need special water diversion and irrigation with high cost.

\section{Expressway construction scheme under the concept of sponge city}

By applying the "sponge" function in the concept of sponge city to the construction scheme of expressway, we hope to create an environment-friendly sponge-type green highway. According to the Technical Guide for Sponge City Construction-Rainwater System
Construction for Low Impact Development (Trial) issued by the Ministry of Housing and Urban-Rural Development, there are three key points for attention in the application of sponge city concept in expressway construction: the protection of the original ecosystem and ecological environment, the restoration and restoration of the surrounding ecology along the expressway, and the application of low impact development and construction concept. The core is to reduce the disturbance of the surrounding ecology if the disturbance needs to be restored; Reasonable and effective plans are made to make full use of rainwater resources. The following will explain the specific application scenarios of low-impact development facilities and analyze the feasibility of its implementation in combination with relevant highway construction projects.

\subsection{The pavement of sponge city concept application}

\subsubsection{Sunken green space and evaporation pool}

Rainwater is imported into the sunken green space through blind ditches and rapids, and some rainwater is absorbed by plants in the green space; Excess rainwater can flow into the underground PP combined water storage module for storage, and it can be used for watering green plants and cleaning road surfaces in the later stage. Green plants in sunken green space usually choose varieties with strong soaking and flood resistance. Sinking green space can partially relieve the drainage pressure of pipe network caused by heavy rainfall in a short time and supplement groundwater resources. In addition, rainwater can be collected and utilized by setting roadside evaporation pool. In Xuwen Port Branch Project of Zhanxu Expressway, large evaporation tanks are set on both sides of subgrade at K514+012, $\mathrm{K} 516+600$, etc., which are used to collect rainwater. It not only prevents a large amount of rainwater from scouring surrounding farmland, but also can be used for irrigation of farmland after storage. In Yangmao expansion project, if some originally designed side ditches and drainage ditches are replaced with sunken green spaces, the land acquisition area may be increased, but the waste of rainwater resources can be greatly avoided.

\subsubsection{Permeable asphalt pavement}


There are three types of permeable asphalt pavement: type I, type II and type III. Type II1 is suitable for sidewalks and vehicle parking areas in expressway service areas, and it can bear medium and small loads, which is usually called "permeable pavement"; Types I and II are generally used in all kinds of newly built and rebuilt highways, which are often called "drainage pavements". Type I can reduce surface runoff and road noise, such as 0GFC pavement; Type II can reduce the burden of road drainage system during heavy rainfall.

(1) Type I sets the sealing layer between the upper surface layer and the middle surface layer, and it discharges rainwater to the adjacent water storage device through the upper surface layer. The advantage is high stability, but the disadvantage is that it can simply reduce surface runoff and eliminate accumulated water. (2) Type II sets the sealing layer between the base layer and the cushion layer. The rainwater reaches the base layer through the surface layer, and it is discharged laterally from the base layer. The advantage is that it can effectively relieve the water accumulation on the road surface, but the disadvantage is that the stability is just worse than that of the I-type. (3) Type III sets the filter layer at the junction of subgrade and pavement, and the rainwater passes through the whole pavement structure layer to reach the bottom of the pavement cushion, then it slowly penetrates into the subgrade through the filter layer and the soil foundation through the subgrade. The advantage is to supplement the groundwater resources, but the disadvantage is to have certain requirements for the permeability of subgrade. In view of the fact that OGFC pavement is a relatively mature drainage pavement at present, and Yangmao expansion project is located in Guangdong Province, which has a lot of rain in rainy season and typhoon season, so it can be considered as a service area pavement. The rainwater is discharged to the adjacent rainwater collection pipeline through the upper layer, and then transported to the built water storage device through the pipe network. It is used for green planting irrigation, toilet flushing, etc., which can greatly improve the utilization rate of rainwater.

\subsubsection{Biological detention facilities}

Ecological ditches can be set on the roadside of expressways, and small green plants can be planted in the ditches, and rainwater runoff on the road surface can be collected through a small ecosystem composed of green plants, soil and microorganisms. This way is a biological detention facility that can also be used in expressway service areas, slopes and green spaces of interchanges. The advantages are wide application range, ornamental, better rainwater runoff treatment effect and lower construction and operation costs, but the disadvantages are as follows: it is not suitable for use in areas with steep terrain and high groundwater level. Infiltration wells can also play the same role, except that seepage wells can treat less rainwater flow and the rainwater quality filtration is not ideal. In addition, grass planting ditch can also be used as a pretreatment measure for biological detention facilities. The shallow dish-shaped ecological drainage ditches in the excavation section of expressways are biological detention facilities used in many projects in Guangdong Province in recent years. For example, Yangmao Extension Project, Baomao Expressway and Zihui Expressway all have shallow dish-shaped ditches in some excavation sections. Shallow dish-shaped ditches can be used in the road sections with short drainage path and long excavation in both directions. Grass is planted in the ditches and covered with health-preserving film, and the film is uncovered when the grass grows luxuriantly. When the shallow dish-shaped side ditch cannot meet the drainage requirements, an open rectangular ditch can be added under it to form a combined side ditch. In order to prevent the influence of weeds on drainage in later period, precast concrete blocks are usually laid at the bottom of shallow dish-shaped ditches.

\subsection{Slope of sponge city concept application}

At present, the ecological protection of slope is widely used, but the influence of growth height on slope should be considered when planting green plants. If the green plants are tall, they may overturn under the action of wind, resulting in damage to slope surface and steps so that the overall stability is affected. At the same time, we should also consider the ability to survive in the natural environment, because the daily slope maintenance is less, and it mainly depends on absorbing natural nutrients to survive. If the poor survival ability leads to rapid death, it will have little effect on stabilizing the slope. Combined with Yangmao expansion 
project, it will have both landscape and ecological protection

The nature of green planting is cultivated on the cutting slope crushing platform, which has a certain ornamental value and improves the slope stability and the level of rainwater absorption and conservation.

\subsection{Interchange with sponge city concept}

By studying the micro-topography of the enclosed area of interchange in detail, the terrain design is carried out, and low-impact development facilities such as wet ponds, reservoirs and sunken green spaces are introduced, which have the function of storing water to a certain extent. The reservoir can quench rainwater, which plays a similar role in filtration and primary sedimentation of sewage treatment. The treated rainwater can be transported to the nearest maintenance work area through pipelines for public toilets, green plant watering, etc. In the enclosed area of Maoming East Interchange of Baomao Expressway, some areas are located in low-lying areas, and rainwater cannot be completely consumed by natural evaporation or infiltration of soil. In order to better solve the problem of accumulated water and improve the level of rainwater conservation, a wet pond connected with the local water system was set up.

\subsection{Service area of sponge city concept application}

Roof drainage in service areas can introduce water into biological detention facilities such as ecological tree ponds through PVC pipes, and it can also reduce overflow of some rainwater by setting green roofs. For small-scale expressway service areas, rain buckets can be used as devices for collecting roof rainwater on sidewalks of service areas, and permeable bricks can be used for pavement due to small load. Permeable brick has the advantages of less surface runoff, increased rainwater infiltration capacity, and adjustment of local microclimate. After the rainwater seeps down through the permeable brick, one part penetrates into the soil, and the other part can be led into the nearby water storage module for storage through the underground diversion devices. The selection of permeable brick materials will greatly affect the infiltration effect of rainwater. As
Yangmao Expressway belongs to the main road of Unicom in western Guangdong, and the traffic volume is large, the areas for pedestrians in the service area can be used by vehicles, so permeable brick pavement cannot be applied to Yangmao expansion project. SWMM model is a more comprehensive and accurate storm flood management model at present, with LID (Low Impact Development) module, which is of great reference significance for the simulation of sponge city application scenarios in China. The measured rainfall data along the expressway is the key to the simulation. The more data years, the more accurate the simulation is. Through the simulation of SWM model, the use effect of various low-impact development facilities can roughly analyzed, and parameters are determined and optimized.

\section{Conclusion}

The application of Highway is mainly to reduce the damage to roads and slopes when the rain reaches its peak. The application of backwater and water storage needs to be tested after large-scale application on expressways. In fact, the concept of sponge city is equivalent to the construction of a new drainage and environmental protection system, aiming at solving a series of water-related problems through a set of evolutionary algorithms. But unfortunately, the establishment of the mathematical model is to import data into the mathematical model for quantitative analysis, so as to complete the planning and design work.

\section{References}

1. Li R. Analysis on application of sponge city concept in expressway design (in Chinese). Building Materials Products \& Application 2019; (1): 106+109. doi: 10.16767/j.cnki.10-1213/tu.2019.01.081.

2. Ren Y, Zhang Y. Design of expressway drainage system based on sponge city concept (in Chinese). Journal of Anhui Institute of Architecture (Natural Science) 2018; 26(6): 47-50.

3. Zhang Y, Chen $\mathrm{W}$, Zhang $\mathrm{R}$, et al. Application status of seepage wells in different regions. Journal of Green Science and Technology 2018; (22): $147-148+154$. 10.16663/j.cnki.lskj.2018.22.058. 